\title{
Leaders' orientations to diversity: two cases from education
}

\section{Introduction}

In many countries, the increasing heterogeneity of commercial, not-for-profit and educational organisations is perceived as a pressure to find ways of using a diverse workforce productively. The primary orientation is one of using 'human resource' effectively to achieve the desired economic or social outcomes (Dick \& Cassell, 2002; Kirton \& Greene, 2005; Packer and Johnson, 1987, Patrickson and Hartman, 2001; Singh 2001). In commercial organisations, demographic or 'business' imperatives are suggested to be more strongly felt than alternative or additional justification deriving from ethical considerations which are assumed to be more evident in public sector organisations (Lorbiecki, 2001; Lumby with Coleman, 2007). This article presents evidence from a further education and a sixth form college in England to explore orientations to diversity in leadership. The two are selected from a larger study of ten cases reflecting a wider range of types of organisations within the English Learning and Skills Sector. It considers theoretical models of action to address diversity issues, describes the research undertaken and presents evidence from the two cases, exploring the conceptualisation of and orientation to diversity of a sample of leaders in each case and how this may relate to action. Finally it considers the ways in which theory might aid our understanding of the interaction of these factors, and how it could be developed to support further reflection and action. A tentative model emerges which relates context to practice.

\section{Conceptualising diversity}


In the UK, public and private sector organisations utilise the word diversity in a multiplicity of ways, but frequently to indicate a range of characteristics in the population of an organisation or community. The focus of this article is diversity and inclusion in educational leadership. Even within the limited field of discourse amongst leaders in education, the word diversity is slippery, used with increasing frequency but indicating a range of different conceptualisations. It appears to be used to indicate the presence within a group/population of whatever size of those deemed 'other'. Who makes judgments of otherness and on what basis renders diversity a concept which is contested, socially constructed and reflective of power relations (Zanoni \& Janssens, 2004). Assessing diversity is related to dimensions both of the proportion of people in the group who are perceived to be other, and to the degree to which one or more persons are deemed to be distant in characteristics from the usually unstated norm of the group. Such distinctions are variously labelled as 'cultural distance' or 'degree of diversity' (Iles \& Kaur Hayers, 1997, p. 107) or 'diversity amount' and 'diversity degree' (Taras \& Rowney, 2007, p. 67).

Zanoni and Janssens (2004) review conceptualisations and differentiate those which focus on individual or groups, those which are broad or narrow and those which relate diversity to business goals or treat it as an essence of the organisation. Kirton and Greene (2005) consider the varying economic and social theoretical bases to conceptualisations, including labour segmentation and feminist approaches. Within each of these there are of course numerous subsets. This article uses particularly the first two distinctions of Zanoni and Janssens (op cit) that is between broad and narrow and individual and group conceptualisations. 
Broad and narrow definitions comprise different dimensions of 'difference' assumed to constitute diversity (Wentling et al., 2000: 36). Broad definitions incorporate a wide range of criteria, including age, disability, religion, sexual orientation, values, ethnic culture, national origin, education, lifestyle, beliefs, physical appearance, social class and economic status (Norton and Fox, 1997). Additionally, diversity is understood by education leaders as a range of attributes, skills and experience involving characteristics such as function, length of service and style of leadership (Lumby et al, 2005). Narrower definitions focus on those characteristics which are perceived as most likely to disadvantage an individual; ethnicity/race, gender, disability and age: the characteristics which have been singled out for antidiscriminatory legislation in Europe and the UK for several decades (Woodhams \& Danieli, 2000). Narrow conceptualisations of diversity which focus on ethnicity, gender and disability are then not narrow in the sense of being blind to the many other characteristics which may be met with attitudes which cause detriment. Rather, they take cognisance of the qualitative difference in the degree of discrimination encountered by particular groups. They are conceptualisations that focus on 'differences that matter' rather than 'those that do not, depending on whether they reinforce inequality' (Reynolds and Trehan, 2003:167).

Whether broad or narrow, such conceptualisations focus essentially on groups and particularly those which arguably have historically encountered the most marked and sustained discrimination and disadvantage. For example, feminist and critical race theories relate to the binary groups of men/women or white/minority ethnic. Litvin (1997) critiques such essentialist categorisation as deriving from scientific taxonomy 
stretching back to Plato. She challenges the assumptions made that human beings can be unproblematically assigned to a particular group:

With its adoption of diversity, managerial discourse has unreflectively incorporated essentialist ontological assumptions from the realm of natural science.

(Litvin, 1997, p. 188)

Her challenge to group based notions of diversity and inequity directs attention to the multiple and unstable identities of individuals, rather than to categories of groups:

The particular differences individuals perceive among one another (as opposed to other, unperceived differences), together with the meanings of those perceived differences, are continually constructed through ongoing processes. There are no essential, innate and immutable characteristics of race, age, gender, disability or other demographic categories. Instead there are history, context, process, interactivity, power relations and change.

(Litvin, 1997, p. 206-7)

This notion of diversity based on individuals is very different to that enshrined in equality legislation. In response to such challenges to group based concepts, intersectionality theory has emerged within the social sciences and argues that the experience of each individual and the intersections of their multiple identities must be considered in order to understand the experience of discrimination and disadvantage (Leathwood, 2005; Valentine, 2007). 
Broad/narrow, group/individual based conceptualisations are each an attempt to order the complexity of humans and their interaction. They simplify, aiming to extract meaning by reducing a degree of complexity which challenges comprehension. The inadequacy of each conceptualisation to fully capture complex human experience is widely suggested. Critiques abound of the inadequacy of current conceptualisations, particularly in terms of their theoretical development and empirical underpinning (Zanoni \& Janssens, 2003; Valentine, 2007; Lumby with Coleman, 2007).

However differences between people either as groups or as individuals are conceptualised, it is the socially constructed inequity brought about by attitudes towards difference which renders difference significant. Who is deciding who is 'different', on what basis and to what end? DiTomaso and Hooijberg (1996: 164-165) describe a process of group acquisition of gain or loss:

People act through social, political, and economic institutions that create, embed, and reproduce the inequality among people which we then call diversity. Diversity is then acted out in the practices of everyday life and interpreted through lenses of moral and ethical reasoning that, when unexamined, legitimate both unearned privilege and unearned disadvantage.

'Difference' is not neutral but construed as offering or denying status and worth. Despite the ubiquitous rhetoric in UK educational policy about 'valuing difference', some characteristics are consistently over time and in multiple locations assigned lesser status and lesser capacity in a variety of ways. The meta-narratives of 
patriarchy and racism are uncovered in education (Blackmore, 2006; Gilborn, 2005). Stone and Collela (1996: 383) note the 'largely automatic, innate, and usually irrevocable' negative emotional reaction to people with disabilities. In common with other public sector workers (Dick \& Cassell, 2002), the universal and structural embeddedness of a negative response to 'difference' is widely overlain by a rhetoric of socially approved orientation to equity amongst educational leaders.

\section{Responding to diversity}

Action builds on policy and encompasses placing responsibility for strategy and its implementation and providing resource. Particular actions in response to diversity issues are fundamentally linked to how they are conceptualised. The underlying paradigms, how the issues and goals are conceived and problematised, have varied throughout different nations and have been more explicitly used to shape legislation and organisational policy during the period from the mid twentieth century (Milliken and Martins, 1996, Gagnon and Cornelius, 2000, Kirton and Greene, 2005, Lorbiecki and Jack, 2000, Singh, 2002). While there are many possible ways of describing how governments and organisations have responded, three approaches have been primary.

\section{$\underline{\text { Equal opportunities }}$}

Early European legislation conceived an issue to be unequal access to education, training, employment and consequently unequal distribution of material and affective rewards. The appropriate response was mooted as treating all equally (Peters, 1996). Men and women, people of different ethnic backgrounds and dis/abled were to be 
treated strictly the same. For example, at job interviews the same questions were to be asked related only to criteria relevant to the post. The focus was on three groups, reflecting issues of gender, race and disability (Liff and Wacjman, 1996). Equal outcomes were not required by law, but the emphasis on achieving representation of the three groups in education/training and employment at all levels was a strong pressure to see the goal as equal outcomes. This 'equal opportunities' approach soon developed more radically by treating particular groups differently, for example, leave arrangements for parents. Such action was in recognition that there would need to be some differences in treatment if equal outcomes were to be achieved rather than merely an aspiration. The disadvantage suffered by some groups would need redress. Equal treatment would be inadequate. Throughout, the consistent goal was achieving 'representation' i.e. a profile at all levels of an organisation's workforce and enjoyment of benefits such as training, which reflected the proportion of women, black and minority ethnic people (BME) and those with disabilities in the local or national population.

\section{Diversity approaches}

More recently different approaches have evolved. Kirton \& Greene (2005: 2) cite '‘managing diversity', 'diversity management' or simply 'diversity policy' as signaling a new orientation. Maxwell et al (1996) distinguish 'diversity' from equal opportunities approaches in a number of ways. They suggest that the focus is on all individuals and not just women, BME and those with disabilities; that difference is to be celebrated and utilized to enhance individuals and the organisation, allowing all to achieve their potential; and that it is the culture of the organisation which is the key 
focus for change. Those who are perceived as different from a white, male, middle class norm are not to be obliged to compete on the terms of those in power, to adapt and to become clones. 'It is the mainstream which is expected to adapt, rather than the diverse individuals required to conform' (Wilson and Isles, 1999: 36). This conception does not take equal treatment as a starting point but rather that people are different along a number of dimensions and they may need to be treated differently. The goal therefore is that the organisational culture should be equally comfortable for all, that is, inclusive. The notion that representation is not the goal but rather the creation of an environment in which the values and culture of all have equal value is a radical departure, but increasingly promoted. Consequently, 'diversity and inclusion' has become something of a mantra in the UK, and specifically in education, reflecting arguably a different conception of the issues and goals to the previous equal opportunities approach.

\section{Capabilities approaches}

The discourse continues to develop worldwide, most recently with the advent of capabilities approaches to equality, based on the work of Sen (1984) and Nussbaum (1999). Their work suggests that attention be paid to process as well as outcomes; that the ongoing quality of life matters as much as summative outcome measures. 'An important starting point is human dignity, the dignity of individuals to live a life they value' (Gagnon and Cornelius, 2000: 71). As expounded by Nussbaum (1999) the approach is based on the development of three capabilities:

- basic capabilities - people's innate talents and attitudes; 
- internal capabilities - the tools people have been equipped with through their education and training, such as numeracy;

- combined capabilities - the interaction between the first two and the environment which allows or does not allow the use and development of basic and internal capabilities.

This is a holistic view which posits that not only development of individuals is needed to allow them to achieve their potential, but that the environment in which they function must be appropriate to allow them to act as they wish. The emphasis is again on all individuals rather than specified groups, and the approach stresses a holistic conception of the wholeness of people's lives and work. The goal is all people empowered to make choices, to achieve their potential and to live life according to their values. Equal outcomes or representation cannot be the goal because people will make different choices.

\section{Conceptual tensions}

Each of the three conceptualisations, equal opportunities, diversity and inclusion and capabilities has been presented as if discrete and clearly distinguishable. In fact, the degree to which they overlap, blend and can be distinguished from each other in concept and the action which follows is highly contested (Thomas and Ely, 1996, Wilson and Isles, 1999, Maxwell et al, 2001). Equal opportunities has been derided as 'entryism' (Davies, 1998:16), that is merely injecting more of any under-represented 
group into the relevant area/level of employment without attention to an inclusive culture (Grogan, 1999). However, some argue that more radical developments of equal opportunities, such as affirmative action, represent an attention to issues of power distribution absent from diversity and inclusion. Others point to tokenism as a result of affirmative action; that is the appointment of a small number of staff with stigmatized identities, taking no further action to ensure the inclusion of appointees. Such action does little or nothing to influence the distribution of power. In either case, though one might argue that each approach has different goals, the actions undertaken under the remit of each are hard to distinguish from those of the other two approaches. All three concepts seem to lead to similar initiatives of efforts to recruit staff with a wider range of visible characteristics, attention to parental needs, positive action training/support for specified groups, cultural awareness training, monitoring of representation etc. All three approaches may currently be found either singly or more usually together in the discourse of diversity and in the action of UK colleges, despite the fact that the goals of each appear to differ (Lumby et al, 2005).

Others have attempted to provide a framework for distinguishing conceptualisations and action approaches. For example, Thomas and Ely (1996 p. 229) identify 'three different perspectives on work force diversity: the integration-and-learning perspective, the access-and-legitimacy perspective, and the discrimination and fairness perspective'. While the efficacy of these categories might be debated, the key point established is that how people conceptualise diversity is strongly related to how they then devise action, if any, in response. 
However, evidence suggests that within educational leadership at least, the goal of representation is the most universal target, partly because accountability and legislative requirements impel equity audits, counting the number and percentage of people by gender, race, disability, age (Commission for Black Staff in Further Education, 2002; Lumby et al, 2005). Rusch (2004) finds that an increase in representation is still the most commonly noted evidence of progress in her USA data related to the development of education leaders. Demonstrating a rise in the percentage of employment of underrepresented groups appears to offer tangible evidence of progress. The article will consider orientations to representation and other goals in two cases in the UK.

This very brief summary of the major developments in conceptualising diversity issues and action in response provides a framework for analysing the conceptualization of diversity by leaders in the two UK cases to be considered. The data can be interrogated to consider the research questions, which were asked of those interviewed and those surveyed by questionnaire:

1. How do leaders understand diversity?

2. What, if any, are seen as the goals?

3. What do the leaders believe to be the pressure(s) for action or inhibitor(s) of action?

4. What degree of pressure is experienced?

5. What action, if any, results? 
The resulting analysis may provide insights into any perceived connection between context, orientation, that is conceptualisation and related goals, and action in the eyes of respondents and as discerned through analysis across respondents.

\section{The research}

The sector under scrutiny

The research reported here draws from a data set related to leadership, leadership development and diversity in the Learning and Skills Sector (LSS) in England. The Learning and Skills Sector is a grouping of different types of institution offering both academic and vocational education at all levels for those from 14 years of age to those in their 80 s or above. The sector comprises sixth form, general and specialist further education colleges, adult and community services, and work-based learning organisations. Each type tends to focus on a particular market. The cases reported here are of two of these types. Sixth form colleges are usually relatively small, with core programmes aimed at an average of approximately 1500 students aged $16-19$ following academic Advanced Level programmes as a preparation for entry to university. General further education colleges are much larger and offer vocational programmes including trade and craft training, academic programmes and vocationally orientated higher education for anything from three to twenty five thousand learners of 14 years of age upwards. General further education colleges somewhat resemble community colleges in the USA and Canada.

\section{Methodology}


A combination of case study and survey methods were employed to gather both rich data on individual perceptions and a broader picture of orientations to leadership and to diversity. The focus in this article is on the perceptions of leaders and consequently it is interview data which is foregrounded to support analysis and discussion of leaders' perceptions and attitudes towards diversity, taking the conceptual frame of broad and narrow conceptualisations (Zanoni \& Janssens, 2004) and their relation to the three approaches to action outlined previously (Singh, 2002).

Ten case examples of different types of organisation in the Learning and Skills Sector in different locations in England were constructed. The sites were selected using a purposive sampling framework. The primary criterion for selection was effective leadership as indicated by learner outcomes, using effectiveness criteria generally accepted within the LSS. Success rates were calculated as qualifications achieved ${ }^{1}$ divided by started qualifications. The initial long list therefore consisted of those organisations in the sector which had data for 1998 to 2002 and showed a more than 5 per cent year-on-year increase in their success rates, that is the percentage of students who achieved the qualifications they set out to achieve increased by five per cent or more each year for five years. The organisations would be considered very successful by many in the UK. The criteria therefore judges effectiveness in supporting student' attainment, but does not relate to the inclusion or exclusion of student entry. The secondary criteria were type of provider and geographical spread. The sampling frame therefore identified from the long list of successful organisations, as previously

\footnotetext{
${ }^{1}$ Started qualifications are the qualifications which leamers com m ilted to achieve at the start of their program $m$ e, excluding leamers who transferred from one program $m$ e to another during their course of study. $Q$ ualifications achieved denote where leamers are accredited $w$ th the qualification they am ed to achieve.
} 
defined, those in each of nine geographic regions. Within each of the nine lists, those willing to participate were identified. A purposive choice was then made to ensure the range of types of organisation were represented. The size and context of each case organisation varied, assessed primarily by the demographic and socioeconomic profile of the local population. The full report, which also presents the methodology in more detail, is available (Lumby et al, 2005).

A detailed analysis of all twelve cases is beyond the scope of one article. Consequently this article purposively selects two cases, each within a very different location demographically, to compare leaders' orientation to diversity and whether it is perceived to be related to the local context. Using data from the UK census of 2001 (Office for National Statistics, 2006) the percentage of minority ethnic people in the locality was identified for each case. While this is only one dimension of diversity, ethnicity emerged from the data of all twelve cases as the characteristic which people were most aware of as indicating diversity and the one which evoked the strongest emotional response. The two cases selected are those situated in the locations with the highest and lowest percentage of minority ethnic people in the local community. The area in which case one was located, for which the pseudonym Seaton is used, had 60 per cent white people (ranked in the lowest five Local Authorities in England and Wales for percentage of white people in the local population). The percentage in the area of case two, Norley, was 99 (ranked in the top hundred of Local Authorities for percentage of white people in the local population).

The use of ethnicity as a variable for selection is in part because assumptions are made by some leaders in the twelve cases that where the population surrounding the case is a large majority white, the community is therefore not diverse. Assumptions 
are apparent which may be interrogated by further analysis: such as, that diversity can be equated with ethnicity, that a certain proportion of the population must have a visibly different skin colour for diversity to be present, that those who may be white but have recent immigrant status and speak a language other than English do not constitute diversity, that other dimensions such as gender, socioeconomic background, disability, religion etc. do not of themselves render a population diverse. The article takes as a premise that all populations are diverse across numerous dimensions but that the two cases selected for focus constitute the most and least diverse external contexts in the eyes of some case leaders at least.

The internal context differs radically also in that one college is large and accepts a wide range of students with a considerable range of courses of varying levels, while the other is focused on a much narrower range of students by age and ability, primarily concerned with A levels. The differences therefore in internal and external context hopefully allow some consideration of the impact if any, on orientation to diversity and action. If the premise is correct, that all populations are diverse, one might anticipate in theory similar levels of interest and energy expended in relation to diversity. However the nature of diversity, however assessed, whether by the range of different characteristics present or the perceived extent of otherness, may also be influential (Taras and Rowney, 2007)

The intention in the original research and in this selection of two cases is not to offer representative conclusions or to generalise on the orientation to diversity in colleges more generally. Rather it is to explore the interrelation of context, concept and action 
in two specific instances in order to contribute to developing theoretical frames to aid leaders' understanding of and further research on diversity issues.

\section{$\underline{\text { Case methods }}$}

The analysis in this article focuses on the data resulting from focus group and individual interviews with senior, middle and first line leaders. Definitions of leaders and leadership are myriad. Following the perceptions of the majority of respondents in the cases colleges, leadership is conceived inclusively. As a respondent in Seaton said 'I don't necessarily see it as senior management'. Others emphasised that lecturers lead, students lead and that leadership itself is not necessarily a formal role but 'leadership is sort of an ownership of how one person perceives their role within the college'. Leadership is therefore taken to be the deliberate transmission of values to inform action, as the most fundamental role of leadership in an educational context (Begley, 2003) and therefore highly relevant to how diversity is addressed (Boscardin \& Jacobson, 1996). Recent theories of distributed leadership support the notion that leadership is a widely spread role and therefore justifies the assumption here that middle and first line leaders can be defined as such (Spillane, Halverson. \& Diamond, 2004). To minimize any power and status difference, separate focus groups for middle, senior and first line leaders were established. The interpretation of first, middle and senior leaders in terms of selecting respondents was left with the organisation, as structures and roles varied, but in general terms, senior leaders held roles such as principal/chief executive, director, head of staff; middle leaders held roles such as head of curriculum area, head of service department, centre co- 
coordinator, and first line leaders held roles such as team leader in a curriculum or support area.

Table 1 about here

\section{$\underline{\text { Analysis }}$}

Typically each group of leaders produced approximately 300 units of text. Each unit comprised the transcript of an individual's single utterance. Units therefore varied in length depending on the period of time for which a respondent spoke, which might be very brief or more prolonged. The analysis paid close attention to how leaders construct meanings; of 'difference' and equality, and how they formulated action in response (Lesko \& Bloom, 1998). Consequently the data was coded using themes related to concepts of diversity, the perceived pressures to consider diversity, the relevance of diversity, actions to achieve diversity and personal experience of diversity issues.

Much of the research data was sensitive and protecting the anonymity of all who contributed was paramount. Therefore, the two cases, one a general further education college and one a sixth form college, are referred to by pseudonym and their location is not divulged. Senior, middle and first line leadership are indicated in the text as SL, ML and FL respectively. FG indicates a focus group and Ind. Int. an individual interview. 


\section{Case one - Seaton College}

\section{$\underline{\text { The context }}$}

Seaton is a community college located in one of the most ethnically diverse and socioeconomically disadvantaged areas in England and Wales (Office for National Statistics, 2006). There are just over 2000 full time and approximately 6,500 part time students on a wide range of courses, including vocational courses, English as a second language and academic courses at a variety of levels. There are about 850 staff of whom 150 are full time permanent. Leaders are diverse with a female principal and unusually, a number of black and minority ethnic people as senior leaders. Twenty staff were interviewed; eleven women and nine men, of whom nine were black or minority ethnic, reflecting the majority of women leaders and the unusually high percentage of BME staff. Respondents were very aware of the diversity they encountered every day, and that this has not always been the case:

I've always been in Seaton so I've seen the changes come about...When I went to the local school here there was one mixed race girl in the whole school and its great now. You come here, you have never seen so many.

(ML FG)

Diversity here is perceived as evident in the proportion of people in the community who are visibly different in terms of skin colour. Representation of the visibly different was evident to other respondents: 
I think you have to look at humanity and I think you look at the wider community and your local community and I think you need to see reflections of those in your student and in your staffing population and that's what you have here.

(SL FG)

Other respondents conceptualised diversity more broadly as including groups with a range of characteristics including varied educational background: 'This area has got a high number of illiterate people and this isn't a cultural thing in terms of which background you come from right' (FL FG), or family status 'Are they parents. Are they single mothers? Are they people who have been excluded from education?' (FL FG), or as in the latter quotation, multiple characteristics together, such as educational background and family status. Both groups, such as 'the illiterate' and 'single mothers', and also individuals are seen as the focus: 'You know recognising people's individuality and telling them to be proud of it' (FL FG).

The nature of the local and student populations was perceived as creating particular pressures. 'Every pattern of refugee migration, every trouble, every upheaval in the world walks through Seaton at some point' (SL FG). Several staff indicated that each major trauma in the world resulted in one or more students who as refugees or migrants would enrol at the college. The environment therefore reflected the conflicts and tensions in world events. As a result, the leaders interviewed were universally united in stating that issues of diversity, that is responding to differing individual and or group needs, and particularly to those who were disadvantaged, could not be 
avoided any more than could the underlying social and economic disadvantage of the local communities. The nature of the wider community and the student profile was translated by respondents into a particular commitment, a particular set of values 'because people need this college so much. They depend on it so much' (FL FG). As a consequence:

I just think that diversity is Seaton's strength anyway. I think it is so embedded in everything we do. We don't stop to think sometimes. You know it's been embedded for such a long time.'

(ML FG)

\section{$\underline{\text { Values }}$}

Leaders at all three levels articulated a commitment to addressing diversity issues:

This college has a huge and overriding commitment ... to try to meet diverse needs. That is an absolute.

(FL FG)

I think people who come into the college and who may be racist, who may be homophobic, who may be sexist, they come in and think what I did at the last place is not going to be tolerated ... so I have got to behave in a very different way.

(ML FG) 
I don't believe you can have equality or equality of opportunity and outcome if you don't have a passionate commitment to the development of diversity in every aspect of the college's business ... You have got to love what it represents and you have got to want to have the struggles.

(SL FG)

Leaders acknowledged the influence of externally mandated targets, but the pressures created by legislation and funding bodies paled beside the consistent and emphatically expressed value driven commitment to support diversity communicated by the focus groups.

\section{Conceptions of diversity}

Diversity was conceptualized by the leaders in multiple ways. The most common conceptualization was based on notions of diversity and inclusion. The differences between people were repeatedly stressed, in tandem with the need to celebrate and view such differences positively. 'Welcome diversity. Celebrate it. Let people feel confident in who they are and what their ability is' (FL Ind. Int.). This attitude, it was stressed, applied not just to teaching staff but also to employees who supported the college in other ways, as cleaners, caterers and maintenance workers.

As outlined earlier, definitions of diversity can be categorized into narrow definitions and broad definitions (Wentling et al, 2000:36). The former focus primarily on race/ethnicity and gender (Kosseck and Lobel, 1996), which are prioritized by legislation. Broad definitions incorporate a much wider range of diversity criteria 
(Norton and Fox, 1997). At Seaton, many respondents conceptualized diversity broadly. 'I think everyone's diverse' (FLM FG). However, while broad definitions were apparent, they were in operation alongside narrow definitions with an acknowledgement of the disadvantage which accrues through a particular characteristic, and specifically race or gender:

You have to understand that our three black members will from time to time have different experiences of the world .....I think you can't lead for diversity if you don't understand the effects of discrimination ... I think you have to understand that sexism and other forms of oppression exist.

(SL FG)

The individuated understanding of diversity shaded at times into a capabilities approach. A holistic view of the individual's life emerged, and of the inseparability of the college from its communities. 'We are active about the things that we think are important to support peoples' self respect, their dignity' (SL FG). A number of respondents stressed their role encompassed leadership of both the college and a community, in local churches and other groups. The isolationism of the professional who arrives, teaches and goes home to another area of the city was depolored:

You need to 'chill' with people from different cultures. Have a few lunchbreaks with them, let them take you down the road. Be a part of the community rather than just serving it - some people do this for years - they come, and deliver, and go back. Roll your sleeves up, get stuck in and stop 
hiding behind bureaucracy or your office door or your title. Be involved with the people.

(FL Ind. Int.)

The third approach, equal opportunities, was also present. At Seaton the emphasis on equal opportunities arose because respondents insisted that sympathy and understanding for those who were oppressed were insufficient. They stressed that there had to be measurable change in terms of the outcomes. Outcomes were therefore monitored to chart many dimensions of change, of which one was representation. The number of staff of particular ethnic origin or gender at each level within the organisation, the number of hirings, promotions, participation in training, complaints, resignations, were all carefully monitored. The fact that all the cleaners were black was described as a failure as much as the lack of BME people at middle management levels. Representation was measured in terms of matching the employee profile, particularly the percentage of people of different ethnic origins, to the local population and the student profile, rather than the much lower percentage in the national population. It mattered to the respondents, as one African Caribbean leader testified:

When I came to this college two years ago one of the first things I noticed was the black members of senior management and to me it was a welcoming sight but at the same time .... the cleaners .... there is no diversity there. All the cleaning staff are black staff. It jumps out at you ... something like that it screams out.

(FL FG) 
The black and minority ethnic people interviewed spoke positively about the values of the college, about the gains made, and the challenges still to be overcome, of which representation was just one. The goal was expressed as achieving 'an organisation where any individual could and should feel comfortable' (SL FG), but also one where each will make the progress they are entitled to expect in terms of hiring, training, promotion and opportunities for meaningful work.

Relating to Zanoni \& Janssen's (2004) framework, respondents in group discussion tended to slide between conceptions of diversity which were group based and individually based, and between narrow and broad, as in this extract from a discussion:

Respondent 1 - I think that the diversity is huge and teaching staff respond to it really well. You know this comes under equal opportunities also you know ... there are so many languages spoken here you know ...... the range of people that come in with different other languages, understanding for me I say to staff that if you just smile that's fine, your making that person feel welcome and ..... you know you could have maybe a deaf student in a main stream class

Respondent 2 - ... senior management has the largest number of black members of staff on there and that's commendable. However from my point of, you probably, I mean I have been here for 10 years and at middle managers, heads of curriculum we have no black members of curriculum at all 
and senior lecturers a few but again very few. It does not represent the actual population of students that we have

Implied in Respondent 1 is a very individualised support for students who have varying and particular needs while respondent 2 emphasises representation of BME which is suggested should reflect the student demographic profile. A bipolar orientation is discernible.

\section{$\underline{\text { Action }}$}

The same ambivalence was evident in policy and action. On the one hand a wide range of equal opportunities based structural features and action was in place, including:

- An equality action plan

- A Race Equality Action Group which reports to the Board of governors

- A Diversity and Equality Co-ordinator

- Codes of practice for the behaviour of staff and students to each other

- Frequent development events in relation to specific aspects of diversity

- Universal staff entitlement to development opportunities

- Supporting networks such as the Black Managers Network

Simultaneously, respondents repeatedly referred to feeling empowered by leadership, 'participative and consultative' (MM FG) which encouraged people to take risks, to 
transfer skills learned in other contexts, to develop, reflecting a diversity and inclusion individual approach to celebrating, empowering and supporting diverse individuals.

\section{Case 2 - Norley College}

\section{The context}

Norley is a sixth form college in a town in a geographic area with an almost entirely white community (99 per cent). It has approximately 500 full-time and 500 part-time students, all but a few aged 16-19, and approximately 80 staff. Seventeen staff were interviewed, five women and twelve men. None were black or minority ethnic as there were no BME leaders at the college. The courses it offers are principally academic Advanced Levels which are seen as a precursor to entry to university. Unlike Seaton, which accepts students onto a wide range of courses whatever their prior achievement, entry to Norley is dependant on evidence of a strong academic performance up to 16 . The college is smaller and less diverse than Seaton in its student population both in terms of ethnic origin and academic achievement.

Some leaders expressed the view that the local community (seen as single entity) was homogeneous. In contradiction, a number of leaders perceived diversity in the population. The exchange which is given below suggests that it is not different cultures, but black people who are seen as indicating diversity, rather than white people from different cultures, or people of Asian origin: 
Female $1-\quad$ If you look at the population of the college it's very, very into a white orientated college.

Male 1 - $\quad$ Norley traditionally has never had any black areas, even now when there's a lot of refugees coming, they do not put black refugees in Norley. They will put east Europeans, etc. but they will not put in black communities. There is a large black community in (another nearby town), and they go there. We do not have a large black area, therefore we do not have a population that would send us a lot of black students. We have certain coloured $^{2}$ students, yes, which reflects the population.

Female 1 - Mostly oriental (male - yes). Oriental or Russian.

The absence of black people in the local population was argued by a number of leaders to result in an absence of diversity issues for the college. As evident in other studies, for example of the constabulary (Dick \& Cassell, 2002) the text reveals arguments which are in tension with the rhetoric in most educational organisation policy documents of an interest in and commitment to diversity and equality (Zanoni \& Janssens, 2003). Staff here generally argued that such issues were largely irrelevant because of three major reasons: first, that what matters most is appointing the best person for the job, second, that representation of all diverse characteristics would be impossible within the small number of leaders in the college and finally, that very few students in the local area are from ethnic minority backgrounds. The goals appear to relate to equal opportunities approaches to action of treating all the same and achieving representation.

${ }^{2}$ Cobur' as used here indicates A sian origin orm ixed race rather than A frican or A frican Caribbean origin. 
$\underline{\text { Values }}$

While not all the leaders interviewed expressed such a view, the attitude of the majority and particularly the senior leadership team in relation to diversity is illustrated by these comments:

I'm tending to be a bit dismissive about this issue to be frank, saying well really all these diversity issues... I personally don't feel very switched on to the idea of diversity...I just feel a little bit amused about it.

(SL FG)

I don't feel that it's an issue at all

(SL FG)

It's not on the agenda - that's my perception ... I don't think diversity by that definition is a problem here

(ML FG).

All three focus groups expressed the view that diversity issues were not relevant. There were some dissenting voices 'If you don't have diversity you have got to do something about it' (ML Ind. Int.), but the majority was somewhat dismissive of the idea of diversity. The most common reason given for this orientation was the absence of BME people in the local population. 


\section{Conceptions of diversity}

The quotations given indicate a conception of diversity which is narrow and group based; primarily the presence of a significant number of BME in the external and internal communities. The focus is on amount of diversity and degree of diversity; the number of visibly different people and the extent of their perceived otherness. Consider the range of arguments brought to bear in this text:

I see it as largely irrelevant - depends on your definition of diversity and what you're seeking to do with diversity. If you're seeking to have representatives of different groups I think it becomes impossible to know where you stop in terms of representing different groups ... but those social groups may not produce leaders that are able ... to provide role models for different types of groups ... Inevitably in the sort of role that we're in, the grouping is not likely to show very clearly anyway unless you're talking about ethnic origin and I'm not sure how relevant that is ... or do you seek diversity simply to meet targets that people say you should be having so many different types of representation in your organisation. So my view is that you appoint the best person for the job ... I don't think many of the students are particularly even aware of different racial groups within the town. There are ethnic minority groups within the college who are not even perceived as being in any way different to everybody else in the college; students are simply not aware of it (SL, FG). 
The argument here proceeds that diversity is irrelevant, that representation of all is impossible, that certain 'social groups' cannot act as role models, that ethnicity is not relevant, that you appoint the best person irrespective of any other characteristics and that anyway students are not aware of BME, and the latter are the same as everyone else.

The narrow conceptualisation of diversity is accompanied by socially constructed assumptions, which appear to conflate small numbers with sameness, there are not many of them and they are the same as us, and to believe that difference equates to incompetence, hence the necessity to always appoint the best person rather than a diverse range. The argument was further developed by other respondents that appointing the best person would lead anyway to equality or possibly representation:

It doesn't matter about the diversity of the management because if you continually employ the best person it tends to even out.

(ML FG)

The definition of 'even out' remains vague. Appointing the 'best' person involved assessing 'their likelihood of fitting into the team' (SL FG). There was an awareness of the process of appointing those with whom you felt comfortable:

There is a tendency to appoint one of your own, to identify with someone, with their background or their demeanor. You think 'I could get on with that person'. ... you do tend to appoint someone who is like you.

(SL FG) 
There is much evidence in other contexts of the tendency to chose the same sex or ethnic groups as oneself (Ibarra, 1992). How 'best' is perceived is often not questioned, and any implicit negative or stereotypical judgments about the relative competence of men and women, the disabled or BEM individuals hidden (Stone \& Colella, 1996). A range of characteristics such as educational experience, background, style were perceived as of more value to leadership than those of ethnicity, gender or disability. For example, to one senior leader 'Diversity of approach or style in leadership is the bit that interests me'. One middle leader explicitly identified two definitions, one related to those characteristics enshrined within the legislation as historically experiencing discrimination, such as gender and race, and a second related to a much wider range of characteristics, and particularly leadership styles. Celebrating difference was generally expressed in relation only to the broader definition and to non visible attributes. The broad conceptualisation allowed respondents to focus on the differences that matter less in terms of disadvantage.

A few individuals acknowledged that the different experience of those with a disability or black and minority ethnic people might be of value, but this was infrequent and dismissed as unlikely to happen in practice and therefore not relevant 'What you might like to do and what's practical are two very different things' (SL FG). 
Leaders had an image of what was ordinary and usual (Tallerico, 2000) which excluded BME people, demonstrated in the semantics in the quotation below which unconsciously presents a norm.

Say fifty Afro Caribbean came into our college now, there would be an incredible amount of effort to make sure they were welcomed in with sort of, with the normal kids.

(FL FG Author's emphasis)

\section{$\underline{\text { Action }}$}

Leaders were both troubled by and mostly somewhat dismissive of the idea that they should take action in relation to diversity. Those applying for leadership positions were treated the same, it was believed, with the justification that the overriding aim was to appoint the best person for the job:

We certainly don't want to get into the state like in America where a certain percentage of the ethnic minority has to be employed, etc, I agree totally with what X said; the best person for the job whether they be male, female, black, white, polka dot, don't care, as long as they're the best person for the job, they get it.

(ML FG)

There was a belief that fairness prevailed: 
If six people have had an interview, a black person wouldn't be treated any differently; they would be treated on what they could contribute and what they would be worth to the organisation

That's because of the nature of the way we would do things anyway ... there would be never any issue of somebody not being treated on a fair basis (SL FG).

This despite the comment about 'a tendency to appoint one of your own' (Author's emphasis). Consequently, action in relation to diversity at Norley was largely confined to the collection of staff demographic statistics and their submission to the funding body as required.

\section{Context, orientation and action}

The final section of the article will consider the two cases in relation to the three elements of context, orientation and action and suggest a theoretical framework for analysing orientations to diversity.

\section{Context}

The context appears to be perceived by staff as of great importance in shaping the values, discourse and action in the two cases. In Seaton, there is a concatenation of internal and external factors which combine to create a strongly felt pressure towards 
viewing diversity as central to the endeavor of the college. The demographic diversity and the socio-economic disadvantage in the local population, combined with an open access policy were perceived as impelling a strong and positive focus on diversity. The presence of large numbers of people with a wide range of visible and non visible characteristics was linked to a broad conceptualisation of diversity and a Janus like propensity of respondents to consider both group and individual aspects of disadvantage. Intersectional thinking was implied by the insistence of some that more than one characteristic needed to be considered in terms of disadvantage, for example family status and educational background. The insistence on links with local communities and community life also suggest some engagement with capabilities approaches. While it cannot be concluded that the external context, and particularly local demographics, were the only cause of such orientations, indeed the powerful commitment of particularly senior staff also appeared key, the respondents themselves believed that the context impelled their attitudes. Analysis suggests that the latter reflect conceptual pluralism in how diversity was conceived and led to multiple actions to address diversity issues inclusive of all three approaches outlined earlier, equal opportunities, diversity and inclusion, and capabilities.

In Norley, context, the perceived homogeneity of the local population, was also perceived as a strong influence. While there is no evidence that the primarily white population caused the concepts and orientations evident in the text, the absence of large numbers of visibly different people seems to be grasped by respondents as a ready tool for numerous justifications of lack of action and for negative beliefs about those who were 'other'. They too believed that local demographics led to their attitudes. Other context factors may also be critical. Norley is selective in who it will 
admit. Staff were proud of the academic results. There was reluctance to admit any change which might conceivably threaten the upward rise of performance, measured by accredited outcomes. Staff spoke of the degree to which they felt allied to other staff and their perception of the relationship between this solidarity and the college's success. Those who share similar backgrounds and attributes are more likely to find satisfaction in working with each other and to reinforce each other positively (Milliken and Martins 1996). Differences within leadership groups, even apparently minor differences such as time of joining the organisation (Ancona and Caldwell 1992) can cause distance between members. Lopez (2003) suggests that power can be discerned by asking who benefits from action. In the case of Norley, both learners and staff benefit from their tight knit internal community which is a perceived factor in the success in raising standards. In contradiction to much rhetoric which normatively asserts that addressing diversity issues is crucial to the success of schools and colleges, this college was successful in the eyes of many while largely ignoring such issues. One might question the values which are thereby passed on to the next generation, but in the area which matters very much to students, staff, inspectors and funders, achieving accredited results, the college is highly successful.

It is possible to conclude, as Rusch (2004) suggests, that in these two cases demographic context has a powerful influence in shaping orientation to issues of diversity. There are significant implications for policy makers, leaders and researchers. Much rhetoric provides a rationale for the necessity to address diversity issues by arguing that leaders will be dealing with increasingly diverse communities (Lopez, 2003). In reality, communities range from extremely diverse to much less so as measured by diversity amount and diversity degree. How is addressing diversity to 
be understood by leaders in communities which are perceived as homogeneous, largely on the basis of the presence of only small number of those who are visibly different, and particularly, black? If, in such contexts, representation as a goal is perceived as impractical and thereby transformed into a justification for taking no action, what then is the goal? If the most prized success, a rise in accredited outcomes, can be achieved in some organisations without addressing diversity issues, what then is the rationale in educational terms for addressing it? Can ethical arguments about equity be realistically seen to offer sufficient pressure to achieve change?

\section{Concepts of diversity}

The leaders of Seaton adopted a 'conceptual pluralism' in relation to how they understood diversity (Bolman and Deal, 1984: 4). The diversity and inclusion approach, with its imperative to respond positively to all employees was embedded, buoyed by political awareness of oppression. However responding to diversity was not seen merely as a process of utilising employee's backgrounds and talents in ways which profited the organisation. Rather the capabilities approach of recognising the wholeness of peoples' lives and their commitment to those with whom they live and work was a parallel conception. Equal opportunities, perceived as indicated by representation, remained a goal, but in the context of repudiating mere 'entryism'. Conceptual pluralism in relation to diversity utilized the range of approaches to action to minimize the potential weaknesses of each and to achieve a platform for action. The practice of the leaders in the college therefore seems some distance from the "silence, blindness and fear" identified in those preparing academic staff (Rusch, 
2004: 15) or practitioners' impatience with diversity issues experienced by Lopez (2003).

Leaders at Norley generally understood diversity as achieving representation in relation to gender and race. However this is translated differentially into a goal for gender, an equal number of women leaders at all levels and in all subunits, and into a reason for taking no action in relation to black and minority ethnic people, for whom the representation target is perceived as impractical and therefore irrelevant. No other goal is substituted. There is an absence of perceived pressure to address issues of gender and ethnicity because there is no 'problem'. A broad conception of diversity and an equal opportunities concept underlay action, or lack of it.

In each of the two case organisations, though there might be a small number of dissenters, there was a dominant discourse. DiTomaso and Hooijberg (1996: 167) draw on social psychology to suggest, 'Individuals develop a 'social identity' with reference to group membership. People then differentiate (or categorize) and give favour to their own group (an ingroup) while evaluating negatively those groups identified as different (outgroups)'. In Norley, the language reflected a positive pride in the incumbent group and a range of anxieties about the 'other', that is people with characteristics different to the majority. Addressing diversity was often equated to affirmative action (that is preference given to the appointment/training/promotion of people from under-represented groups), and consequent fears that quality would suffer and represented groups would be disadvantaged. Such fears were reflected in semantics which unconsciously not only create a 'different' group, but ascribed to the 
group lesser abilities and depicted them as a source of threat, of having not the 'best' leaders. 'The land of the other' was clearly discernible (Rusch, 2004: 32).

In Seaton the 'land of the other' was understood very differently, not as an alien place, unknown, feared, but as here, now, a source of strength, the present college. It is not that racism and sexism have disappeared, 'I am constantly aware of diversity and it is a challenge and a struggle' (SL Ind. Int.), but rather they are not experienced in relation to an outgroup, those external to the college, but as part of the warp and weft of the ingroup, the staff and learners. 'Difference' is not a negative. Explicitly one leader states 'I have no fear of difference' (FL Ind. Int.). The contrasting discourses in Seaton and Norley, each influenced by context, lead to very different understandings of the need for and implementation of action.

\section{$\underline{\text { Action }}$}

At Seaton staff believed that values based on a strong commitment to a positive orientation to diversity were embedded not only in the strategic plans of the college but in every aspect of daily practice. At Norley the little relevant action which took place is episodic, that is isolated, disjointed, and separate from core organizational activities (Dass and Parker, 1999). The issue is not that Norley should attempt representation on its staff of the national percentage of people with particular characteristics. If it primarily draws staff from the local population, it is understandable that the staff profile would represent the local community profile. What is troubling is how the near absence of a single dimension of diversity in the 
local community, blackness, becomes a ready justification for leaving undisturbed attitudes to the 'other' which may be exclusionary.

\section{Theorising orientation to diversity}

While this article has presented only two cases and no conclusions can be reached which are generalisable, the data and its analysis has suggested that a theoretical frame to aid categorisation of orientations to diversity may be useful in pursuing further work with educational organisations. The model presented therefore is one of numerous attempts by researchers to provide frameworks. It may be useful in exploring further data from the other ten cases in this study.

One might analyse the differing approaches to diversity as presented in the two cases as leading for diversity or leading with diversity. Leading for diversity essentially targets the injection of more people from under-represented groups into leadership positions. Its goal is representation. This was the conceptual underpinning of respondents at Norley. Leading with diversity aims to achieve structures and a culture which are equally supportive of all, so that people whatever their nature or background can work productively while remaining true to themselves. This was the conceptual underpinning of respondents at Seaton. Additionally one might consider the degree of engagement with diversity issues, which was strong at Seaton and weak at Norley. Four possible approaches to addressing diversity emerge, modeled in Figure 1: 
Figure 1 about here

The $\mathrm{y}$ axis represents a scale of the degree of importance given to achieving representation, that is, working for diversity. The $\mathrm{x}$ axis represents a scale of the degree of importance given to achieving an inclusive culture, that is, working with diversity. The result is a tentative model of four different orientations to diversity.

\section{Indifferent}

The bottom left cell is indifferent, where though there may be minimum compliance with external requirements, for example in collecting data for equity audits, there is little interest in addressing diversity issues.

\section{Entryist}

The top left cell is the entryist orientation. Representation is seen as the sole or primary aim. There is little interest in changing the existing culture as a result of or prerequisite for appointing more people from under-represented groups. Rather the assumption is that all appointed must do a 'good job' in the style of the dominant group.

\section{Multicultural}

The bottom right cell is a multicultural orientation. In organisations where there may be little realistic possibility in the short term of achieving diverse representation, for 
example in terms of ethnicity, such as in very small schools or educational organisations situated in rural or small communities, leaders are still committed to building awareness of and inclusion of difference. This may be on ethical grounds, derived from the values of staff, and on educational grounds, deriving from a determination to equip students with values and attitudes appropriate to their future in a diverse society, even while learning in a relatively homogeneous organisational community.

\section{Systemic}

The top right cell is a systemic approach where representation in all aspects of the organisation is an embedded objective as a subset of aiming at a just community, which colonizes 'the land of the other' (op cit) as its own, and works to deepen understanding of and resistance to racism, sexism and other prejudice within a diverse organisational community. Such a stance and the actions which follow are embedded and central to the values and goals of the organisation.

The latter two cells do not imply a context related determinism. Those organisations located in small or relatively homogeneous communities can adopt a systemic approach, just as the other three cells might describe the orientation of organisations located in very diverse communities. However the model is a tentative step towards developing a framework which recognises the futility of urging leaders to respond to ever more diverse communities, when in fact some communities may remain largely the same as previously. Some may believe, as did most Norley staff, that insistence that attention is paid to diversity in a context like Norley is an attempt to fix a 
problem that does not exist. This article questions the assumptions which attach 'problem' to diversity and assume diversity relates only or primarily to a particular demographic profile and not to all communities.

While individual leaders may undoubtedly hold differing positions, in the two cases presented in the article an organisational position was discernible in a dominant discourse. The two cases could be tentatively placed in two cells, Seaton in the top right, systemic, and Norley in the bottom left, indifferent. The positioning of each is strongly related in respondents' perceptions to the local demographic context.

The model emerges from the analysis of two cases, and relates to only two of the four cells. More research is needed on the nature of the pressures which influence orientation, the educational and social effects of each orientation, and to test the model.

Within the ten case studies, Seaton was the sole organisation to exhibit a systemic orientation. Optimism must be muted as a result. Far more research is needed on the interplay of the triad of context, discourse and action before understanding can take the leap needed to develop policies and practice which are more than rhetorical positions of commitment to equity and which are compelling to leaders in all contexts.

\section{References}

Ancona D.G, and Caldwell D.F. (1992). Demography and design: predictors of new product team performance. Organization Science, 3, 321-41. 
Begley, P. (2003) In Pursuit of Authentic School Leadership Practices, in Begley, P. \& Johansson, O. (Eds.) The Ethical Dimensions of School Leadership, London, Kluwer Academic.

Bergen, B. (1988) Only a Schoolmaster: Gender Class and the Efforts to Professionalize Elementary Teaching in England 1870-1910, in J. Ozga, (Ed) Schoolwork: Approaches to the Labour Process of Teaching, Milton Keynes, Open University.

Blackmore, J. (2006) Social Justice and the Study and Practice of Leadership in Education: A feminist History, Journal of Educational Administration and History, Vol. 38, No. 2, pp. 185-200.

Bolman, L. and Deal, T. (1984) Modern Approaches to Understanding and Managing Organizations, San Francisco, Jossey-Bass.

Commission for Black Staff in Further Education (2002) Challenging Racism: Further Education Leading the Way: The full report of the Commission for Black Staff in Further Education, London: Commission for Black Staff in Further Education.

Boscardin, M. \& Jacobson, S. (1996) The Inclusive School: Integrating diversity and solidarity through community-based management, Journal of Educational Administration, Vol. 35, No. 5, pp. 466-476. 
Dass, P. and Parker, B. (1999) Strategies for Managing Human Resource Diversity: From resistance to learning, Academy of Management Executive, Vol. 13, No 2. pp $68-80$

Davies, L. (1998) Democratic practice, gender and school management, in P. Drake and p. Owen. (Eds) Gender and Management in Education, London, Trentham.

$\begin{array}{lllll}\text { DfES The standards } & \text { site, accessed } & \text { online } & \end{array}$ http://www.standards.dfes.gov.uk/schooldiversity/what_is_school_diversity/?version $=1$

Dick, P. \& Cassell, C. (2002) Barriers to managing Diversity IN UK Constabulary: The Role of Discourse, Journal of Management Studies, Vol. 39, No.7, pp.953-976.

DiTomaso, N. and Hooijberg, R. (1996) Diversity and the Demands of Leadership, The Leadership Quarterly, 7 (2) pp. 163-187.

Dreachslin, J.L., Hunt, P.L. and Sprainer, E. (2000) 'Workforce diversity: implications for the effectiveness of health care delivery teams', Social Science and Medicine, 50, pp.1403-1414.

Gagnon, S. and Cornelius, N. (2000) Re-examining workplace equality: The capabilities approach, Human Resource Management Journal, 10 (4) pp. 68-87. 
Gillborn, D. (2005) Education policy as an act of white supremacy: whiteness, critical race theory and education reform, in Journal of Education Policy, Vol., 20, No. 4, pp. $485-505$.

Great Britain (1975). Sex Discrimination Act. London: HMSO.

Great Britain (1976). Race Relations Act. London: HMSO.

Grogan, M (1999) Equity/Equality Issues of Gender, Race and Class, Educational Administration Quarterly, 35 (4) pp. 518-536.

Home Office (2006) Training and career development Accessed online 5.7.06 http://police.homeoffice.gov.uk/training-and-careerdevelopment/PRDLDP/?version=1

Ibarra, H. (1992) Homophily and differential returns: Sex differences in network structure and access in an advertising firm. Administrative Science Quarterly. Vol 37(3) 422-447.

Iles, P. \& Kaur Hayers, P. (1997) Managing Diversity in Transnational Project Teams. A tentative model and case study, Journal of Managerial Psychology, Vol. 1, No. 2, pp. 95-117.

Johnston, W. and Packer, A. (1987) Workforce 2000: Work and Workers for the 21st Century, Hudson Institute, Indianapolis. 
Kirton G. and Greene A. M. (2005). $2^{\text {nd }}$ Edition The dynamics of managing diversity. Oxford: Butterworth Heinemann.

Kossek, E.E. and Lobel, S.A. (1996) Managing Diversity: Human resource strategies for transforming the workplace, Oxford: Blackwell.

Leathwood, C. (2005) 'Treat me as a human being - don't look at me as a woman': femininities and professional identities in further education, Gender and Education, Vol. 17, No. 4 pp387-409.

Lesko, N. \& Bloom, L. (1998) Close encounters: truth, experience and interpretation in multicultural teacher education, Journal of Curriculum Studies, 30(4), pp. 375-395.

Lopez, G.R. (2003) The (Racially Neutral) Politics of Education: A Critical Race Theory Perspective, Educational Administration Quarterly, 39 (1) pp. 68-94.

Lorbiecki, A. and Jack, G. (2000) Critical Turns in the Evolution of Diversity Management, British Journal of Management, Vol. 11, Issue 3, pp.17-31.

Lumby, J. Harris, A. Morrison, M. Muijs, D. Sood, K. Glover, D. Wilson, M. with Briggs A. R. J. and Middlewood, D. (2005) Leadership, Development and Diversity in the Learning and Skills Sector, London, LSDA.

Lumby, J. with Coleman, M. (2007) Leadership and Diversity: Challenging Theory and Practice in Education, London, Sage. 
Maxwell, G.A., Blair, S. \& McDougall, M. (2001) Edging towards managing diversity in practice, Employee Relations, Vol. 23, No. 5, pp. 468-482.

Milliken, Frances J. and Martins, Luis L.(1996) Searching for common threads: Understanding the multiple effects of diversity in organizational groups, Academy of Management Review, Vol. 21 Issue 2, p402 - 434.

Norton, J.R. and Fox, R.E. (1997) The Change Equation: Capitalising on diversity for effective organisational change, Washington DC: American Psychological Association.

Nussbaum, M. (1999) Women and equality: the capabilities approach, International Labour Review, Vol. 138, No. 3, pp. 227-245.

Office for National Statistics (2006) Census 2002. Accessed online 8.8.06 http://www.statistics.gov.uk/census2001/profiles/00EB-A.asp

Patrickson, M. and Hartmann, L. (2001) Human resource management in Australia: Prospects for the twenty-first century, International Journal for Manpower, 22 (3) pp. 198-206.

Reynolds, M. and Trehan, K. (2003) Learning from Differences, Management Learning, 34 (2) pp. 163-180. 
Rusch, E.A. (2004) Gender and race in leadership Preparations: A Constrained Discourse, Educational Administration Quarterly, 40 (1) pp. 14-16.

Sen. A. (1984) Resources, Values and Development, Cambridge MA. Harvard University Press.

Singh, V. (2002) Managing Diversity for Strategic Advantage, London, Council for Excellence in Management and Leadership.

Spillane, J. P., Halverson, R. \&Diamond, J. B. ( 2004) Towards a theory of leadership practice: a distributed perspective. Journal of Curriculum Studies, Vol. 36 Issue 1, pp. 3-34.

Stone, D. \& Colella, A. (1996) A Model of Factors Affecting the Treatment of Disabled Individuals in Organizations, Academy of Management Review, Vol. 12, No. 2, pp. 352-401.

Tallerico, M. (2000) Gaining Access to the Superintendency: Headhunting, Gender and Color, Educational Administration Quarterly, 36 (1) pp.18-43.

Taras, V. \& Rowney, J. (2007) Effects of Cultural Diversity on In-Class Communication and Student Project Team Dynamics: Creating Synergy in the Diverse Classroom, International Studies in Educational Administration, 35(2) pp. $66-81$ 
Taylor, S. (2004) Researching educational policy and change in 'new times': using critical discourse analysis, Journal of Education Policy, 19 (4), pp. 433-451.

Thomas, D. \& Ely, R. (1996) Making Differences matter: A New Paradigm for Managing Diversity, Harvard Business Review, Vol. 74, No. 5, pp. 79-90.

Taras, V. \& Rowney, J. (2007) Effects of Cultural Diversity on In-Class Communication and Student Project Team Dynamics: Creating Synergy in the Diverse Classroom, International Studies in Educational Administration 35 (2) 6681.

Stone, D. \& Colella, A. (1996) A Model of Factors Affecting the Treatment of Disabled Individuals in Organizations, Academy of Management Review, Vol. 12, No. 2, pp. 352-401.

Valentine, G. (2007) Theorizing and Researching Intersectionality: A Challenge for Feminist Geography, The Professional Geographer, 59 (1) pp. 10-21.

Wentling, R.M. and Palma-Rivas, N. (2000) 'Current Status of Diversity Initiatives in Selected Multinational Corporations', Human Resource Development Quarterly, 11 (1), pp.35-60.

Wilson, E. \& Isles, P. (1999) Managing Diversity - an employment and service delivery challenge, The International Journal of Public Sector Management, Vol. 12, No. 1, pp. 27-48. 
Woodhams, C. \& Danieli, A. (2000) Disability and diversity - a difference too far? Personnel Review, Vol. 29, No. 3, pp, 402-416.

Zanoni, P. \& Janssens, M. (2004) Deconstructing Difference: The Rhetoric of Human Resource Managers' Diversity Discourses, Organization Studies, Vol. 25, No1, pp5574. 